\title{
Tibial tunnel enlargement and joint instability after anterior cruciate ligament reconstruction. A prospective comparison between autograft and allograft ${ }^{1}$
}

\author{
Qiang Zhang', Guangliang Hao", Mingyong Gu'", Xuecheng Cao'v
}

'MD, Division of Orthopedics, The General Hospital of Jinan Military Command, China. Intellectual, scientific, conception and design of the study; technical procedures; manuscript writing.

"MD, Division of Orthopedics, The General Hospital of Jinan Military Command, China. Acquisition, analysis and interpretation of data; statistical analysis; manuscript writing.

I'MD, Division of Orthopedics, The General Hospital of Jinan Military Command, China. Acquisition, analysis and interpretation of data; manuscript writing.

IVMD, Division of Orthopedics, The General Hospital of Jinan Military Command, China. Intellectual and scientific content of the study, technical procedures, manuscript preparation, critical revision, final approval.

\begin{abstract}
Purpose: To investigate tibial tunnel widening and knee instability after ACL reconstruction with hamstring autograft or irradiated soft tissue allograft.

Methods: Eight-two patients were divided into two groups: autograft group and allograft group. Radiographic and clinical evaluations were performed.

Results: Seventy patients were followed up with median of 36.3 months (range 36-38 months). Tibial tunnel widening was at or greater than $30 \%$ for nine patients in the autograft group and 15 patients in the allograft group $(P=0.0417)$. The average percentage of tibial tunnel widening was $26.7 \pm 4.0 \%$ and $29.7 \pm 5.3 \%$ in autograft and allograft groups, respectively $(P=$ $0.0090)$. Knee range of motion was not affected by the reconstruction operation or different grafts. Thigh atrophy improved significantly within 24 months after $\mathrm{ACL}$ reconstructions in both groups. ACL reconstruction with the allograft leaded to less knee stability than that with the autograft from one year after operation $(P=0.0023)$. There was no significant difference between two groups with respect to Lysholm score $(P=0.1925)$ and Tegner score $(P=0.0918)$ at the final follow-up.

Conclusion: The allograft group reported significantly more tibial tunnel widening and knee instability compared with the autograft group.

Key words: Anterior Cruciate Ligament Reconstruction. Autografts. Allografts. Joint Instability.
\end{abstract}




\section{Introduction}

The anterior cruciate ligament ( $A C L)$ reconstruction is an effective method to treat $\mathrm{ACL}$ injury in order to restore knee stability, decrease risk of medial meniscal tears ${ }^{1}$ and improve functional outcome. Approximately 200,000 ACL reconstructions were performed in the United States alone each year ${ }^{2}$. Various types of grafts, including autografts, allografts, and synthetic grafts, have been successfully used to replace the torn ligaments in $\mathrm{ACL}$ reconstruction. Within last two decades, the use of the allograft has progressively risen for its advantages of predictable graft size, smaller cosmetic incision, no donor site morbidity, shorter operation time, availability for multiligament injury, less pain, easier rehabilitation, and decreased incidence of post-operative knee stiffness. It was estimated that allografts were used in about $20 \%$ of primary $A C L$ reconstructions in the USA ${ }^{3}$. Some randomized controlled and prospective trials have verified that both autografts and allografts showed satisfactory and comparable outcomes ${ }^{4}$. But the utilization of the allograft in $\mathrm{ACL}$ reconstruction also raises a series of problems such as sterilization and preservation of the allograft, disease transmission, the immune response to the allograft tissue by the host, and delayed graft incorporation, which will affect the biomechanical properties and clinical outcomes of allografts. A study by Maletis et al. demonstrated that the use of the allograft resulted in significantly higher revision rate ${ }^{5}$. Zeng et al. ${ }^{6}$ performed a systematic review to compare the allograft with the autograft in $\mathrm{ACL}$ reconstruction and found that the allograft had greater abnormal stability rate than the autograft.

No matter what kind of the graft is used, bone tunnel enlargement is a common phenomenon after the $\mathrm{ACL}$ reconstruction?. As a result, the diameter of the tibial or femoral tunnel becomes big, which is not desirable when the patient needs to accept the revision surgery caused by intraoperative or postoperative complications. On the other hand, many previous studies have shown an association between tunnel enlargement and worse results such as anterior and rotational instability of the knee ${ }^{8}$. The aim of the study is to investigate prospectively the association between grafts and bone tunnel enlargement, along with the effect of grafts on the clinical results such as the knee stability after $\mathrm{ACL}$ reconstruction. We hypothesized that outcomes of $A C L$ reconstruction with the hamstring autograft would be superior to that with the soft tissue allograft with regard to bone tunnel enlargement and knee stability.

\section{Methods}

The study obtained the permission of the Medical Ethical Committee of our institution. The purpose and procedure of the study were provided to all patients and written informed consents were obtained from them.

From June 2011 to May 2014, we prospectively enrolled 82 patients with $\mathrm{ACL}$ injuries. The types of injury were defined as follows: military training $(n=42)$, sports $(n=28)$, and motor vehicle $(n=12)$. The inclusion criteria were implemented as follows: age of 18 to 35 years, unilateral $\mathrm{ACL}$ reconstruction, no axial malalignment or instability, no ipsilateral knee grade III or IV cartilage injury, no additional grade III collateral ligament injury, no arthritis, and no undergo more than one-third of the meniscus excision. All patients had a positive anterior drawer test and Lachman's sign. The $\mathrm{ACL}$ injury was diagnosed during arthroscopy and treated by single-bundle $A C L$ reconstruction with quadrupled hamstring autografts $(n=46)$ or soft tissue allografts $(n=36)$. The soft tissue allograft used in $A C L$ reconstruction included the hamstring allograft $(n=16)$, the anterior 
tibialis allograft $(n=14)$, and the Achilles allograft $(n=6)$. All the allografts were freshfrozen, sterilized with 1.5 Mrad of irradiation, and provided by a tissue bank approved by China State Food and Drug Administration.

The same senior surgeon performed the operations with epidural anesthesia using arthroscopic single-bundle ACL reconstruction techniques. A complete arthroscopic examination was performed. The cartilage injury was evaluated, and the torn menisci were repaired firstly. Remnant fibres of the ruptured $A C L$ were preserved as completely as possible and the tibial tunnel was drilled using the method described by Lee et al. ${ }^{9}$. The femoral tunnel was prepared independently through the anteromedial portal at the 10-o'clock position for the right knee or the 2-o'clock position for the left knee. For the patient in the autograft group, the hamstring autograft tendon was harvested and folded to create a four-strand graft after pre-tension. For the patient in allograft group, the fresh-frozen graft was thawed in $37^{\circ} \mathrm{C}$ isotonic saline for 45 minutes and then preconditioned under tension of $70 \mathrm{~N}$ for 15 minutes by use of the Graftmaster board (Arthrex, Naples, FL, USA). The Rigidfix system was used for femoral fixation. When a bioabsorbable interference screw that was $1 \mathrm{~mm}$ larger than the diameter of the tunnel was used for tibial fixation, the screw was advanced just a few millimeters below the joint line.

After $A C L$ reconstruction, functional braces were used immediately in both groups, and the patients followed the same rehabilitation procedure. Quadriceps isometrics and straight leg raise were initiated as soon as possible to increase quadriceps strength and prevent skeletal muscle atrophy. $20^{\circ}$ of flexion should be achieved for the first week, $40^{\circ}$ during the second week, $70^{\circ}$ the third week, and $90^{\circ}$ in the fourth week. The recovery of the full range of motion (ROM) was scheduled six weeks postoperatively. Within six weeks after operation, the ROM was limited from full extension to $20^{\circ}$ of flexion as long as the knee flexion had achieved the required angle three times a day. Partial weight-bearing with crutches was permitted after four weeks, and full weight-bearing began three months after operation. The patients started partial squats and toe raises to develop quadriceps strength further. Here we emphasized the importance of the quadriceps exercises and required patients to perform them for at least two years until they achieved full ROM and good muscular control of the legs. Patients were permitted to return to full sports 12 months after operation and were followed up for more than three years. The radiographic and clinical evaluations were performed by an experienced orthopaedic surgeon who was blinded regarding whether patients had autografts or allografts.

At one week postoperatively and the final follow-up, antero-posterior and lateral plain radiographs were made in a relaxed and fully extended position. The measurement of the tunnel diameter was performed on the computer screen with a built-in digital calliper in a digital radiography system (PowerHis Viewer, Dongjian Corporation, Beijing, China) as described previously ${ }^{10}$. The distance between the two inner margins of the bone tunnel perpendicular to the axis of the tibial tunnel at the widest point were measured as the diameter of the tunnel. The bioabsorbable interference screw could be identified clearly on the radiograph of one week postoperatively. If the margin of the screw overlapped with one of the two margins of the tunnel, it would be used as one of the inner margins to measure the tunnel diameter. The tibial tunnel diameters on both antero-posterior and lateral plain radiographs were measured three times, and then the mean of six values was recorded for subsequent calculation. The diameter of 
the tibial tunnel at one week after operation was used as the reference diameter, and the diameter of the tibial tunnel at the final followup was used as the final diameter. The tunnel enlargement was reported in percentages using the following expression: ([final diameter-reference diameter]/reference diameter) $\times 100 \%$.

Objective evaluations, which included ROM of the knee, thigh atrophy, and KT2000 arthrometer testing, were performed preoperatively and at six months, 12 months, 24 months, and the final follow-up postoperatively. Lysholm Knee Rating Scale and Tegner Activity Level Scale were used as subjective evaluations and were performed preoperatively and at the final follow-up.

ROM of the knee: The ROM was measured with a goniometer with the patient in the prone position, and comparison was made between the two sides. According to the International Knee Documentation Committee (IKDC) guideline, the passive motion deficit was graded as normal $\left(0^{\circ}\right.$ to $5^{\circ}$ lack of ROM), nearly normal ( $6^{\circ}$ to $15^{\circ}$ lack of ROM), abnormal ( $16^{\circ}$ to $25^{\circ}$ lack of ROM), and severely abnormal (> $25^{\circ}$ lack of ROM).

Thigh atrophy: The circumference of the thigh $8 \mathrm{~cm}$ above the superior pole of the patella was measured in full knee extension. Thigh atrophy was defined as a percent of thigh circumference of the involved knee less than that of the contralateral knee: ([circumference of the contralateral thigh-circumference of the involved thigh]/ circumference of the contralateral thigh) $\times 100 \%$.

KT-2000 arthrometer testing: The KT2000 arthrometer (MEDmetric Corporation San Diego, CA) was used to quantitatively measure the knee laxity with a posterior force of $20 \mathrm{lbs}$ at $30^{\circ}$ knee flexion. During the test, the legs were kept relaxed with the patient in the supine position. The contralateral leg was tested first, and then the side-to-side difference in maximum anterior displacement was recorded. Three measurements of each knee were made with an interval of five minutes and the average value was calculated and rounded to the $0.1 \mathrm{~mm}$.

Lysholm Knee Rating Scale measured daily living activity level and eight factors were rated to produce an overall score on a point scale of 0 to 100 . Tegner Activity Level Scale classified both sports and work activity levels into one questionnaire using a 0 to 10 gradient.

GraphPad Prism 5 (San Diego, CA) was used to perform statistical analysis and create the artwork. Fisher's exact test was used for categorical variables. The unpaired $t$ test was performed to compare continuous variables between the autograft and allograft group, and a comparison of continuous variables in the same group was performed using paired $t$ test. A $P$ value of $<0.05$ was considered statistically significant.

\section{- Results}

Of these 82 patients, 12 were lost to follow-up (eight in the autograft group, four in the allograft group), and then data from the remaining 38 patients in the autograft group and 32 in the allograft group were presented in this study. The demographic data, including gender, age, involved side, preoperative activity level, time interval between injury and operation, meniscal injury, and followup period, were collected, and there was no significant difference between the two groups (Table 1). The average length of follow-up was 36.3 months (range 36-38 months). In our series, there was no complication, including graft failure, infection, nerve injury, arterial injury, deep thrombosis, or infectious disease transmission, during the whole follow-up period. 
Table 1 - Demographic data and characteristics of patients.

\begin{tabular}{llll} 
& $\begin{array}{l}\text { Autograft group } \\
(\mathbf{n = 3 8})\end{array}$ & $\begin{array}{l}\text { Allograft group } \\
(\mathbf{n = 3 2})\end{array}$ & P-value \\
\hline Age at surgery (years) & $23.8 \pm 5.2$ & $26.1 \pm 6.3$ & 0.1560 \\
Involved side (right/left) & $24 / 14$ & $23 / 9$ & 0.4392 \\
Preoperative activity level & $84 \pm 11$ & $82 \pm 12$ & 0.8586 \\
Time-interval between injury and operation (months) & $12.1 \pm 10.7$ & $13.7 \pm 9.0$ & 0.6975 \\
Meniscal injury (\%) & 37 & 33 & 0.5532 \\
Follow-up period (months) & $36.2 \pm 1.5$ & $36.4 \pm 1.1$ & 0.8851 \\
\hline
\end{tabular}

\section{Radiographic evaluation}

The contours of the tibial tunnels were prominent on the antero-posterior and lateral plain radiographs at one week postoperatively and the final follow-up. Tibial tunnel enlargement was at or greater than $30 \%$ for nine patients in the autograft group and 15 patients in the allograft group. The Fisher's exact test revealed significant difference between the two groups $(P=0.0417)$. Moreover, the autograft group had less percentage of the tibial tunnel enlargement than the allograft group (Table 2).

Table 2 - Tibial tunnel enlargement at the final follow-up and Lysholm and Tegner score preoperatively and at the final follow-up of both groups.

\begin{tabular}{llllll} 
& \multicolumn{2}{l}{ Tibial tunnel } & Lysholm score & \multicolumn{2}{l}{ Tegner score } \\
& enlargement & Preoperative & Final follow-up & Preoperative & Final follow-up \\
\hline Autograft group & $26.7 \pm 4.0 \%$ & $62.0 \pm 10.5$ & $90.7 \pm 5.6^{\mathrm{a}}$ & $5.03 \pm 1.28$ & $7.61 \pm 1.35^{\mathrm{a}}$ \\
Allograft group & $29.7 \pm 5.3 \%$ & $59.8 \pm 10.8$ & $88.6 \pm 7.3^{\mathrm{b}}$ & $4.75 \pm 1.52$ & $7.06 \pm 1.29^{\mathrm{b}}$ \\
$P$-value & 0.0090 & 0.4012 & 0.1925 & 0.4131 & 0.0918 \\
\hline
\end{tabular}

${ }^{a}$ Autograft group: preoperation:the final follow-up $P<0.0001$.

${ }^{b}$ Allograft group: preoperation:the final follow-up $P<0.0001$.

\section{Clinical evaluation}

Concerning ROM, all data were collected and listed in Table 3. According to the normal rate (normal and nearly normal) and abnormal rate (abnormal and severely abnormal) of ROM, there was no significant difference between the two groups and the ROM was similar for the same group at all time points.

Table 3 - Range of motion of both groups at all time points ( $n$ ).

\begin{tabular}{|c|c|c|c|c|c|c|c|c|c|c|}
\hline & \multicolumn{2}{|c|}{ Preoperative } & \multicolumn{2}{|c|}{6 months } & \multicolumn{2}{|c|}{12 months } & \multicolumn{2}{|c|}{24 months } & \multicolumn{2}{|c|}{ The final follow-up } \\
\hline & $\begin{array}{l}\text { Autograft } \\
\text { group }\end{array}$ & $\begin{array}{l}\text { Allograft } \\
\text { group }\end{array}$ & $\begin{array}{l}\text { Autograft } \\
\text { group }\end{array}$ & $\begin{array}{l}\text { Allograft } \\
\text { group }\end{array}$ & $\begin{array}{l}\text { Autograft } \\
\text { group }\end{array}$ & $\begin{array}{l}\text { Allograft } \\
\text { group }\end{array}$ & $\begin{array}{l}\text { Autograft } \\
\text { group }\end{array}$ & $\begin{array}{l}\text { Allograft } \\
\text { group }\end{array}$ & $\begin{array}{l}\text { Autograft } \\
\text { group }\end{array}$ & $\begin{array}{l}\text { Allograft } \\
\text { group }\end{array}$ \\
\hline Normal & 33 & 27 & 28 & 24 & 30 & 25 & 30 & 26 & 29 & 26 \\
\hline $\begin{array}{l}\text { Nearly } \\
\text { normal }\end{array}$ & 3 & 2 & 6 & 4 & 5 & 4 & 5 & 3 & 5 & 3 \\
\hline Abnormal & 2 & 3 & 2 & 2 & 2 & 2 & 2 & 2 & 3 & 2 \\
\hline $\begin{array}{l}\text { Severely } \\
\text { abnormal }\end{array}$ & 0 & 0 & 2 & 2 & 1 & 1 & 1 & 1 & 1 & 1 \\
\hline
\end{tabular}


Table 4 presented the parameters of preoperative thigh atrophy and thigh atrophy at each time point of follow-up. Continuously, thigh atrophy improved significantly within 24 months after the $A C L$ reconstruction in both groups. Thigh atrophy did not significantly change between 24 months and 36 months after operation for either group. No significant difference was found preoperatively and at all follow-up times between the two groups.

Table 4 - Thigh atrophy of both groups at all time points (\%).

\begin{tabular}{llllll} 
& Preoperatively & $\mathbf{6}$ months & $\mathbf{1 2}$ months & $\mathbf{2 4}$ months & $\mathbf{3 6}$ months \\
\hline Autograft group & $4.08 \pm 1.93$ & $2.62 \pm 1.38$ & $1.87 \pm 1.10$ & $0.92 \pm 1.01^{\mathrm{a}}$ & $0.94 \pm 0.95^{\mathrm{b}}$ \\
Allograft group & $4.33 \pm 1.66$ & $2.73 \pm 1.46$ & $2.13 \pm 1.05$ & $1.26 \pm 1.10^{\mathrm{c}}$ & $1.11 \pm 0.91^{\mathrm{d}}$ \\
\hline
\end{tabular}

Values are mean $\pm \mathrm{SE}$.

a Significant difference between 12 and 24 months after operation in the autograft group $(P<0.0001)$.

${ }^{\mathrm{b}}$ No significant difference between 24 months after operation and the final follow-up in the autograft group $(P=0.6642)$.

'Significant difference between 12 and 24 months after operation in the allograft group $(P<0.0001)$.

${ }^{d}$ No significant difference between 24 months after operation and the final follow-up in the allograft group $(P=0.1436)$.

According to the KT-2000 arthrometer testing, significant improvement in knee instability was achieved by ACL reconstruction with either autografts or allografts, and there was no significant difference compared between the two groups preoperatively and at six months follow-up. However, there was a gradual increase of knee instability over time at follow-up in the allograft group, and the autograft group showed significant better knee stability than the allograft group from one year after operation onwards (Table 5, Figure 1).

Table 5 - KT-2000 measurements of side-to-side difference in both groups at all time points (mm).

\begin{tabular}{llllll} 
& Preoperatively & $\mathbf{6}$ months & $\mathbf{1 2}$ months & $\mathbf{2 4}$ months & $\mathbf{3 6}$ months \\
\hline Autograft group & $6.2 \pm 1.6$ & $2.1 \pm 0.7^{*}$ & $2.4 \pm 0.8^{*}$ & $2.2 \pm 0.7^{*}$ & $2.2 \pm 0.7^{*}$ \\
Allograft group & $6.4 \pm 1.5$ & $2.5 \pm 1.1^{*}$ & $3.1 \pm 1.1^{*}$ & $3.3 \pm 1.2^{*}$ & $3.4 \pm 1.5^{*}$ \\
$P$-value & 0.5772 & 0.0639 & 0.0023 & $<0.0001$ & $<0.0001$ \\
\hline
\end{tabular}

Values are mean $\pm \mathrm{SE}$.

*Significant difference between postoperation and preoperation in the same group $P<0.0001$.

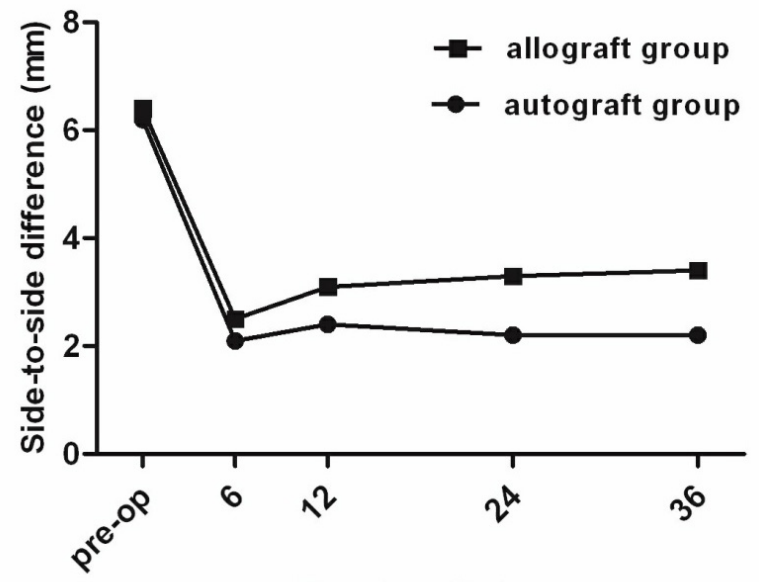

Time (months)

Figure 1 - KT-2000 measurements of side-to-side difference in both groups at all time points. A gradual increase of knee instability over time at follow-up in the allograft group; $P<0.01$ comparing knee stability between allograft group and autograft group from one year after operation onwards.
Both Lysholm and Tegner scores had significant improvement from preoperative to the final follow-up in the two groups. However, no significant difference between the two groups was detected (Table 2).

\section{Discussion}

With the increase of sports popularity and exercise intensity, $A C L$ injury incidence increases year by year and $A C L$ reconstruction technology matures gradually. But there are still many controversial issues in the process of $\mathrm{ACL}$ reconstruction, and graft selection is one of the examples. Various grafts have their own advantages and disadvantages, and so far, there has not been a perfect graft material. 
Though autografts are the most widely used reconstruction materials, they have their own disadvantages such as donor site morbidity and longer operation time. Allografts can overcome the above disadvantages, and are affirmed by surgeons. Allografts include the soft tissue allograft and the tendon-bone allograft. Many reports have been made concerning the allograft, and influences of the tendon-bone allograft on tunnel enlargement have been investigated with different conclusions ${ }^{11}$. But there are rare researches about the influences of the soft tissue allograft on bone tunnel enlargement. We conducted a prospective study to evaluate the difference between the hamstring autograft and the soft tissue allograft in $A C L$ reconstruction and found that tibial tunnel enlargement and knee instability were more significant in the allograft group than in the autograft group, but in terms of ROM, thigh atrophy, and subjective functional outcomes, both groups were found to be similar.

Scientific and reasonable rehabilitation program closely relate whether or not the patients can return to their preinjury sports activity level. Compared with native ACL or the autograft, the fresh-frozen allograft has less favorable biomechanical characteristics ${ }^{6}$, delayed biologic remodeling ${ }^{12}$, and slower tendon-bone incorporation ${ }^{13}$. In addition, van Eck et al. have proved that the allograft failure was associated with early return to sports and high sports intensity ${ }^{14}$. So we advocate a less aggressive rehabilitation, and this opinion is consistent with that of Dustmann et $a{ }^{15}{ }^{15}$. At the first six weeks postoperatively, ROM rehabilitation program is formulated on a weekly basis, and if the involved knee has achieved the required flexion angle for every week, knee flexion will be restricted to avoid repeated tensile force on the graft. We discourage patients from early weight-bearing and return to sports, but we encouraged them to do lower extremity strength training. Patients must pay attention to performing unilateral quadriceps strength-training, and don't try to improve quadriceps strength through walking and jogging, because most patients use the contralateral limb more subconsciously when they are walking or jogging.

Among eight patients whose ROM was graded as abnormal at six months after operation, only one patient eventually returned to normal. So the six-month was a critical period for the knee ROM rehabilitation, and patients should exercise the knee ROM to the normal level in this period of time. In addition, because four of the five patients with abnormal ROM before ACL reconstruction didn't restore normal knee ROM at the final follow-up, we suggest that the $A C L$ reconstruction will be delayed until knee ROM comes into normal or near normal level. According to the research of Lo et al. ${ }^{16}$, we evaluate quadriceps strength recovery by measuring thigh atrophy. We use a percentage to express the degree of thigh atrophy because the circumference of each patient's contralateral thigh had a large disparity, and the difference between the involved thigh and the contralateral thigh cannot reflect the severity of thigh atrophy accurately. In both groups, patients have significant difference in the circumference of the thigh between the involved thigh and the contralateral thigh within two years after operation, which indicates that thigh muscle strength will recover to normal level until two years after operation.

In the present study, we use the diameter of the tibial tunnel at one week after operation as the reference diameter rather than the size of the drill that has been used to prepare the bone tunnel, because when an interference screw is used to fix the graft, it compresses the bone tunnel walls, and leads to early tunnel enlargement ${ }^{17}$. Struewer et al. ${ }^{18}$ had a more than 10 years follow-up about tunnel enlargement after $A C L$ reconstruction and proved that the tunnel diameter did not change further after two years postoperatively. 
Therefore we compared tunnel enlargement at three years of follow-up, and believed that the tunnel diameter at that time could truly reflect the final tunnel status. According to our research, tunnel enlargement was more pronounced for the $A C L$ reconstruction using the soft tissue allograft versus the hamstring autograft.

When analyzing the reasons, several possible explanations can be found. The first is the immune response that the host generates against the allograft. Though the sterilization and preservation processes will damage most the donor cells, but they cannot eliminate the risk of immunological rejection responses completely ${ }^{19}$. Moreover, the collagen of extracellular matrix also contains a small amount of histocompatibility antigens and is able to result in a detectable immune response ${ }^{20}$. The transplant rejection causes chronic inflammation around the allograft and releases various cytokines that lead to bone resorption eventually ${ }^{19}$. In the allograft group, the tibial tunnel diameters of different patients vary greatly, in our opinion, because the constitution of the patient is different, and the immune response to the allograft has individual differences. Secondly, the final stability of graft in bone tunnel depends on the biological healing rather than temporary mechanical fixation. Before tendon-bone healing, the micromotion between graft and bone tunnel will exert stress on the tunnel wall and result in bone tunnel enlargement ${ }^{21}$. It has been shown in many studies that the healing of the allograft to the bone is slower and less complete than that of the autograft ${ }^{12,13}$, so the micromotion will last for a longer time and the tunnel enlargement will be more obvious. Thirdly, after $A C L$ reconstruction, synovial fluid will leak into and scatter along the bone tunnel. With knee extensor and flexor activity, the pressure will force more synovial fluid to flow into the tunnel. The synovial fluid contains cytokines, including IL-6, IL-8 and tumor necrosis factor, proteolytic enzymes, and growth factor inhibitors, which are known to results in osteolysis and bone tunnel enlargement by means of inhibiting bone formation and stimulating osteoclastic activity ${ }^{22}$. Through second-look arthroscopy, Lee et al. ${ }^{23}$ compared synovial coverage of the graft after $A C L$ reconstruction with autografts or allografts and found the autograft had earlier and better synovial coverage. Synovial coverage and synovialization of the graft are able to seal the tunnel intra-articular entrance so as to decrease the back flow of the synovial fluid and inhibit tunnel enlargement.

Knee instability after ACL reconstruction with the allograft has been verified by some authors. In a 6.9 years of follow-up of 107 patients, Tian et al. ${ }^{24}$ found that the allograft group displayed significantly more laxity than the autograft group at all time points postoperatively. By meta-analysis, Kraeutler et al. ${ }^{25}$ assessed the knee stability after $\mathrm{ACL}$ reconstruction with autografts or allografts, and concluded that there was a lower level stability in the allograft group. The etiology of knee instability caused by the allograft is multifactorial, and accumulating evidences suggest that sterilization and preservation of the allograft ${ }^{26}$ and immunological factors ${ }^{27}$ are involved. The allograft that we used went through the process of irradiation, freezing, and thawing, which could affect their structural and mechanical properties. Guo et al..$^{28}$, comparing different sterilization methods for allografts, found that the $\gamma$-irradiated allograft group had a statistically poorer KT-1000 result compared with the fresh-frozen allograft group. In a study with sheep, Scheffler et al. demonstrated that the fresh-frozen allograft had delayed recellularization and revascularization, and significant antero-posterior instability was found $^{12}$. The present study observes that the allograft group has more obvious tibial tunnel enlargement, which is also one of the reasons that lead to more antero-posterior instability ${ }^{28}$. Though the allograft used in $\mathrm{ACL}$ 
reconstruction is associated with significant tibial tunnel enlargement and knee instability, it appears not to affect the subjective clinical evaluation significantly with a follow-up at least 36 months. The same result was reported by some other authors. Fules et al. ${ }^{29}$ evaluated tibial bone tunnel enlargement with the use of MRI scan cross-sectional area measurement and clinical outcomes following $\mathrm{ACL}$ reconstruction, and stated that there was no correlation between tunnel enlargement and Lysholm subjective self-evaluation score. Goodwillie et al. analyzed post-reconstruction results, and found that there was no necessary correlation between severe generalized joint instability and functional outcomes at longterm follow-up ${ }^{30}$. In our study, the allograft group has lower daily living and sports activity levels, but after statistical analysis, the difference is not significant compared with the autograft group. In our opinion, complete recovery of quadriceps muscle strength through the positive rehabilitation is able to prevent the knee from giving way and compensate the discomfort caused by joint instability.

Our study has a few limitations. The first is the fact that it is not a randomized trial. The allograft that we used is a harvested cadaver tendon, so there are ethical and ideological problems for some patients. We must explain to patients in detail about the sources, advantages, and disadvantages of both grafts, and which kind of grafts to be used is determined according to the patient's own preference. Some patients were unwilling to receive the cadaveric tissue, so we couldn't conduct a randomized trial. Second, allografts that we used included the hamstring allograft, the anterior tibialis allograft, and the Achilles allograft. The three kinds of allografts maybe have slight differences in aspect of morphological and biomechanical properties. When we analyzed the results, we didn't take the effect of the type of allografts on the results into account. Finally, the number of patients in our trial is low comparatively, and the small sample size will to some extent affect the statistical results.

\section{- Conclusions}

The irradiated soft tissue allograft used in $A C L$ reconstruction may increase the prevalence of tibial tunnel enlargement and aggravate knee instability, even though it doesn't affect the subjective clinical outcomes three years after operation. When surgeons decide to perform $A C L$ reconstruction with the irradiated soft tissue allograft, it is important for them to consider the above disadvantages and choose the most suitable graft for a certain patient. The new sterilization and preservation methods of the allograft need to develop and utilize to reduce the damage to it.

\section{References}

1. Morris RC, Hulstyn MJ, Fleming BC, Owens $\mathrm{BD}$, Fadale PD. Return to play following anterior cruciate ligament reconstruction. Clin Sports Med. 2016;35(4):655-68. doi: 10.1016/j.csm.2016.05.009.

2. Yazdi H, Moradi A, Sanaie A, Ghadi A. Does the hyperextension maneuver prevent knee extension loss after arthroscopic anterior cruciate ligament reconstruction? J Orthop Traumatol. 2016;17(4):327-31. doi: 10.1007/s10195-016-0408-9.

3. Chechik O, Amar E, Khashan M, Lador R, Eyal G, Gold A. An international survey on anterior cruciate ligament reconstruction practices. Int Orthop. 2013;37(2):201-6. doi: 10.1007/s00264-012-1611-9.

4. Sun K, Zhang J, Wang Y, Xia C, Zhang C, Yu T, Tian S. Arthroscopic reconstruction of the anterior cruciate ligament with hamstring tendon autograft and fresh-frozen allograft: a prospective, randomized controlled study. Am J Sports Med. 2011;39(7):1430-8. doi: $10.1177 / 0363546511400384$.

5. Maletis GB, Chen J, Inacio MC, Love RM, Funahashi TT. Increased risk of revision after anterior cruciate ligament reconstruction with soft tissue allografts 
compared with autografts: graft processing and time make a difference. Am J Sports Med. 2017;45(8):1837-44. doi: $10.1177 / 0363546517694354$.

6. Zeng C, Gao SG, Li H, Yang T, Luo W, Li YS, Lei GH. Autograft versus allograft in anterior cruciate ligament reconstruction: a metaanalysis of randomized controlled trials and systematic review of overlapping systematic reviews. Arthroscopy. 2016;32(1):153-63. e18. doi: 10.1016/j.arthro.2015.07.027.

7. Stolarz M, Ficek K, Binkowski M, Wróbel Z. Bone tunnel enlargement following hamstring anterior cruciate ligament reconstruction: a comprehensive review. Phys Sportsmed. 2017;45(1):31-40. doi: 10.1080/00913847.2017.1253429.

8. Järvelä T, Moisala AS, Paakkala T, Paakkala A. Tunnel enlargement after double-bundle anteriorcruciate ligament reconstruction: a prospective, randomized study. Arthroscopy. 2008;24(12):1349-57. doi: 10.1016/j. arthro.2008.07.018.

9. Lee BI, Min KD, Choi HS, Kim JB, Kim ST. Arthroscopic anterior cruciate ligament reconstruction with the tibial-remnant preserving technique using a hamstring graft. Arthroscopy. 2006;22 (3):340.e1-7. doi: 10.1016/j.arthro.2005.11.010.

10.Kobayashi $M$, Nakagawa $Y$, Suzuki T, Okudaira S, Nakamura T. A retrospective review of bone tunnel enlargement after anterior cruciate ligament reconstruction with hamstring tendons fixed with a metal round cannulated interference screw in the femur. Arthroscopy. 2006;22(10):1093-9. doi: 10.1016/j.arthro.2006.05.017.

11.Ge $Y$, Li H, Tao H, Hua Y, Chen J, Chen $\mathrm{S}$. Comparison of tendon-bone healing between autografts and allografts after anterior cruciate ligament reconstruction using magnetic resonance imaging. Knee Surg Sports Traumatol Arthrosc. 2015;23(4):954-60. doi: 10.1007/s00167013-2755-x.

12.Scheffler SU, Schmidt T, Gangéy I, Dustmann M, Unterhauser F, Weiler A. Fresh-frozen free-tendon allografts versus autografts in anterior cruciate ligament reconstruction: delayed remodeling and inferior mechanical function during long-term healing in sheep. Arthroscopy. 2008;24(4):448-58. doi: 10.1016/j.arthro.2007.10.011.
13.Gulotta LV, Rodeo SA. Biology of autograft and allograft healing in anterior cruciate ligament reconstruction. Clin Sports Med. 2007;26(4):509-24. doi: 10.1016/j. csm.2007.06.007.

14.van Eck CF, Schkrohowsky JG, Working ZM, Irrgang JJ, Fu FH. Prospective analysis of failure rate and predictors of failure after anatomic anterior cruciate ligament reconstruction with allograft. Am J Sports Med. 2012;40 (4):800-7. doi: 10.1177/0363546511432545.

15.Dustmann $M$, Schmidt T, Gangey I, Unterhauser FN, Weiler A, Scheffler SU. The extracellular remodeling of free-soft tissue autografts and allografts for reconstruction of the anterior cruciate ligament: A comparison study in a sheep model. Knee Surg Sports Traumatol Arthrosc. 2008;16(4):360-9. doi: 10.1007/s00167007-0471-0.

16.Lo YP, Hsu KY, Chen LH, Wang CJ, Yeh WL, Chan YS, Chen WJ. Simultaneous arthroscopic reconstruction of the anterior and posterior cruciate ligament using hamstring and quadriceps tendon autografts. J Trauma. 2009;66(3):780-8. doi: 10.1097/TA.0b013e31815d9b88.

17.Ugutmen E, Ozkan K, Güven M, Sener N, Altintas F. Early tunnel enlargement after arthroscopic ACL reconstructions. Acta Orthop Belg. 2007;73 (5):625-9. PMID: 18019919.

18.Struewer J, Efe T, Frangen TM, Schwarting T, Buecking B, Ruchholtz S, Schüttler KF, Ziring $E$. Prevalence and influence of tibial tunnel enlargement after isolated anterior cruciate ligament reconstruction using patella-bonetendon-bone-graft: long-term follow-up. Orthop Rev (Pavia). 2012;4(2):e21. doi: 10.4081/or.2012.e21.

19. Höher J, Möller HD, Fu FH. Bone tunnel enlargement after anterior cruciate ligament reconstruction: fact or fiction? Knee Surg Sports Traumatol Arthrosc. 1998;6(4):23140. doi: $10.1007 / \mathrm{s} 001670050105$.

20.Xiao Y, Parry DA, Li H, Arnold R, Jackson WJ, Bartold PM. Expression of extracellular matrix macromolecules around demineralized freeze-dried bone allografts. J Periodontol. 1996;67(11):1233-44. doi: 10.1902/jop.1996.67.11.1233.

21.Wilson TC, Kantaras A, Atay A, Johnson 
DL. Tunnel enlargement after anterior cruciate ligament surgery. Am J Sports Med. 2004;32(2):543-9. doi: $10.1177 / 0363546504263151$.

22.Zysk SP, Fraunberger $P$, Veihelmann $A$, Dörger $M$, Kalteis T, Maier M, Pellengahr C, Refior HJ. Tunnel enlargement and changes in synovial fluid cytokine profile following anterior cruciate ligament reconstruction with patellar tendon and hamstring tendon autografts. Knee Surg Sports Traumatol Arthrosc. 2004;12 (2):98-103. doi: 10.1007/ s00167-003-0426-z.

23.Lee JH, Bae DK, Song SJ, Cho SM, Yoon $\mathrm{KH}$. Comparison of clinical results and second-look arthroscopy findings after arthroscopic anterior cruciate ligament reconstruction using 3 different types of grafts. Arthroscopy. 2010;26 (1):41-9. doi: 10.1016/j.arthro.2009.06.026.

24.Tian S, Wang B, Liu L, Wang Y, Ha C, Li Q, Yang $X$, Sun $K$. irradiated hamstring tendon allograft versus autograft for anatomic double-bundle anterior cruciate ligament reconstruction: midterm clinical outcomes. Am J Sports Med. 2016;44(10):2579-88. doi: 10.1177/0363546516655333.

25.Kraeutler MJ, Bravman JT, McCarty EC. Bone-patellar tendon-bone autograft versus allograft in outcomes of anterior cruciate ligament reconstruction: a meta-analysis of 5182 patients. Am J Sports Med. 2013;41(10):2439-48. doi:

\section{$10.1177 / 0363546513484127$.}

26.Guo L, Yang L, Duan XJ, He R, Chen GX, Wang FY, Zhang Y. Anterior cruciate ligament reconstruction with bone-patellar tendonbone graft: comparison of autograft, freshfrozen allograft, and $\gamma$-irradiated allograft. Arthroscopy. 2012;28(2):211-7. doi: 10.1016/j.arthro.2011.08.314.

27. Ménétrey J, Duthon VB, Laumonier T, Fritschy D. "Biological failure" of the anterior cruciate ligament graft. Knee Surg Sports Traumatol Arthrosc. 2008;16(3):224-31. doi: 10.1007/s00167-007-0474-x.

28. Quatman CE, Paterno MV, Wordeman SC, Kaeding CC. Longitudinal anterior knee laxity related to substantial tibial tunnel enlargement after anteriorcruciate ligament revision. Arthroscopy. 2011;27(8):1160-3. doi: 10.1016/j.arthro.2011.02.039.

29.Fules PJ, Madhav RT, Goddard RK, NewmanSanders A, Mowbray MA. Evaluation of tibial bone tunnel enlargement using MRI scan cross-sectional area measurement after autologous hamstring tendon $\mathrm{ACL}$ replacement. Knee. 2003;10(1):87-91. PMID: 12649033.

30.Goodwillie AD, Shah SS, McHugh MP, Nicholas SJ. The Effect of postoperative KT-1000 arthrometer score on longterm outcome after anterior cruciate ligament reconstruction. Am J Sports Med. 2017;45(7):1522-8. doi: $10.1177 / 0363546517690525$.

\section{Correspondence:}

Xuecheng Cao

Department of Orthapaedic Surgery

The General Hospital of the Jinan Military

Command

No. 25, Shifan lu, Jinan, Shandong China, 250031

Phone: +8613678821711

caoxuecheng63@126.com

Received: Aug 8, 2017

Review: Oct 6, 2017

Accepted: Nov 9, 2017
Conflict of interest: none

Financial source: none

\footnotetext{
${ }^{1}$ Research performed at Division of Orthopedics, The General Hospital of Jinan Military Command, China.
} 